\title{
Evaluation of Switching Over Voltages on High Voltage Circuit-Breakers in 400/132kV Fajr II Electrical Substation
}

\author{
Behzad Sedaghat and Majid Esmi
}

\begin{abstract}
One of the main concerns in establishing high voltage electrical substation is switching over voltages. According to the typical design of these substations all of the circuit-breakers connected to overhead lines or transformers must have switching shunt resistance or synchronizing switch to limit the switching over voltages. These parallel resistances are very expensive and so the synchronizing switches. In fact in some cases, there are some technical factors that can lower the price of the solution for the overvoltage problem. In this paper the effects of length of overhead lines on switching over voltages are analyzed, details of system components modeling are outlined. This study can propose a method for needs assessment of shunt resistances or synchronizing switches. System components are implemented in EMTDC/PSCAD software. Simulations are executed for "Fajr II 400/132KV GIS substation" during substation design period and the results show that there is no need for shunt resistors or synchronizing switches for the CBs of the substation.
\end{abstract}

Index Terms - Power system, switching over voltage, circuit breaker, high voltage substation.

\section{INTRODUCTION}

\section{A. Switching in High Voltage Systems}

Switching of circuit-breakers may cause transient over-voltages in the power system and destroys equipment installation in electrical substations. Switching over-voltage is one of the main concerns in insulation coordination of substations. Damages and interruptions in the system are minimized if insulation coordination is designed properly. The cause of these damages may be steady state, dynamic or transient over-voltages. In substations, over-voltages are mostly occurred when CBs that are connected to overhead lines and power transformers are switched. High voltage CBs insulation may not withstand these over-voltages.

In the higher-voltage systems, voltages produced by switching operations are much more importance than atmospheric disturbances. There is, however, a limit to the magnitude of the atmospherically induced voltages [1]. Switching over voltages may arise, for example, from opening of unloaded transmission lines or highly inductive circuits, such as unloaded transformers or shunt reactors [1].

Switching transients are divided into two main parts: normal \& abnormal switching transients. In this paper, based on ref [2] abnormal transients are circumstances in which

Manuscript received February 9, 2012; revised March 12, 2012.

Behzad Sedaghat is with Monenco Iran consulting engineers of MAPNA Group. Iran.

Majid Esmi is with Azad University, Saveh branch, Saveh, Iran. voltage or current are far in excess of twice its normal peak values.

Insulation of high voltage CBs typically can tolerate over voltages up to 2.5 times over its nominal voltage. If the value of the over voltage excesses the limit electrical arcs will be produced between terminals and other metal parts.

\section{B. Abnormal Switching Over-Voltages}

The main reason that leads to switching over voltages is the current suppression. The current carried by a power switch does not normally cease when its contacts are separated, rather the current continues to flow through an arc until it reaches its periodic zero [2]. Physically the trapped magnetic energy release causes the abnormal over voltage. The details of what happened in the system before and during abnormal over-voltages are discussed in section III.

This paper investigates the most probable and severe causes of switching over-voltages. These events can be classified into two main sections: line energizing and de-energizing due to faults or network maneuvers, and energizing and de-energizing no-load or low-load power transformers.

\section{Voltage Limiting Methods}

There are several limiting methods for reducing switching over voltages but in fact two of them are most popular. At conventional switching the phase position at each switching occasion will be random, which means that switching in a very unfavorable phase position is likely. Pre-insertion resistor is one of the conventional methods.

The other method to solve the problem is to apply synchronizing system that controls the CBs time of switching. The controller of the synchronizing switches enables controlling of the switching moment so that switching always takes place in a pre-determined phase position selected to eliminate the switching transients or limit them as far as possible [3].

\section{Fajr II Substation as Case Study}

Fajr II 400/132kV Substation configuration is divided in to two parts: "1 $1 / 2$ breakers" in $400 \mathrm{KV}$ A.I.S. side and "Simple Busbar with bus section" in $132 \mathrm{KV}$ side. The entire system configuration from upstream "Mahshahr II 400KV" substation to 132KV G.I.S. Substation of "Fajr II Gas power plant" is shown in Fig. 1 [4]. A 400KV overhead transmission line connects "Mahshahr II substation" and "Fajr II substation". This is a $25 \mathrm{~km}$ double-circuit transmission line. Two 132KV outgoings are connected to the "Fajr II power plant" through high voltage cable. Other two outgoings are connected to the Fajr II utilities. 


\section{SYSTEM COMPONENTS}

This section includes a brief description of the system components, modeling and implementation of these components in PSCAD/EMTDC software. In this study, switching on no-load transformer and 400KV transmission line are analyzed. For simplification "Mahshahr II S.S" is assumed as an infinite bus and "Fajr II power plant" is assumed as a simple voltage sources with internal resistor. Detailed modeling of the basic components can be found in [5].

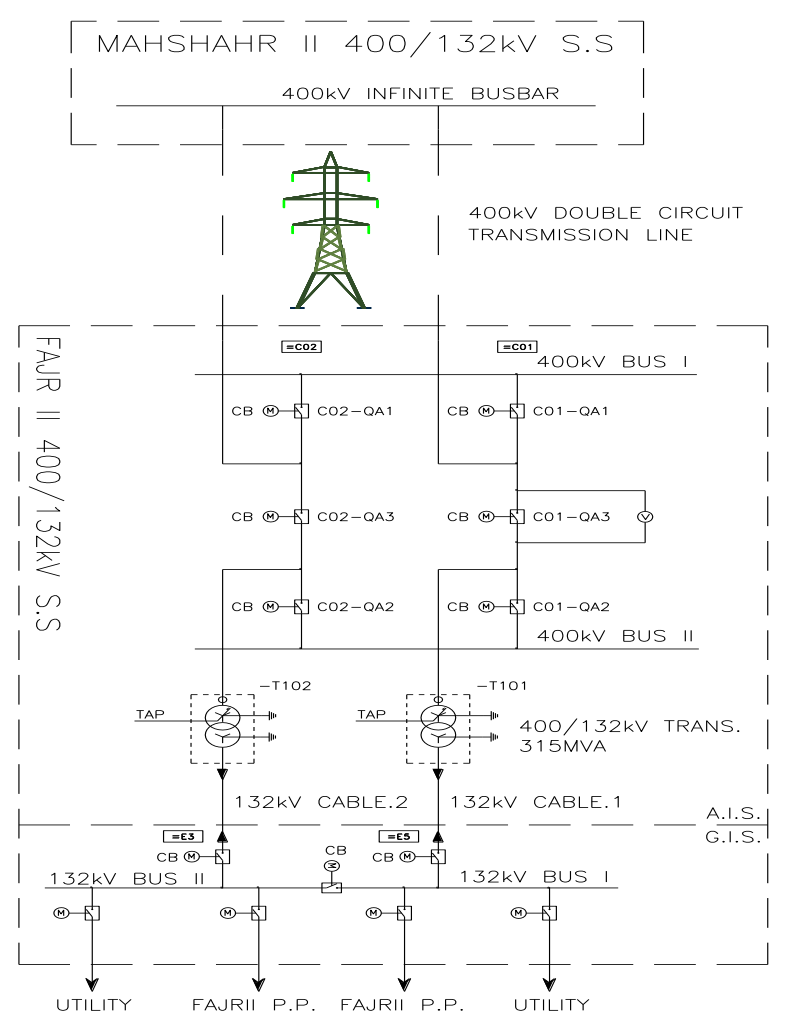

Fig. 1. System Configuration.

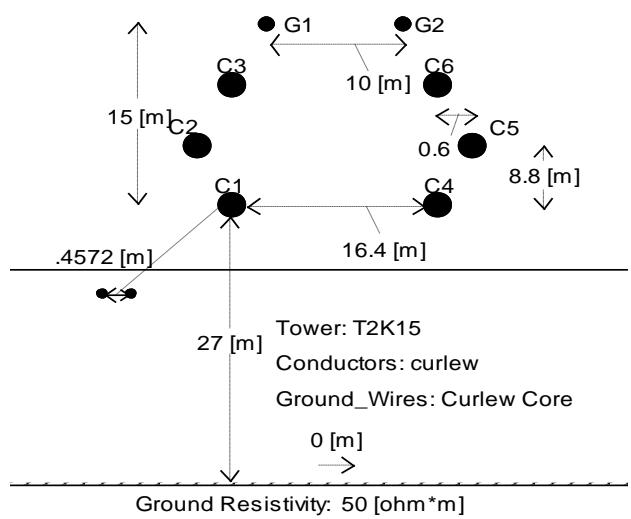

Relative Ground Permeability: 1.0

Earth Return Formula: Deri-Semlven

Fig. 2. Transmission line configuration

\section{A. 400kV Transmission Lines}

Modeling of transmission lines in a network requires dimensions and technical data. The transmission line data includes: transmission line conductor diameter and resistance per unit length of transmission line, phase transformation data and distance between phase bundle, spacing between phases, shield wire diameter and resistance per unit length, height of each conductor and shield wire at the tower and sag to midspan, tower dimensions, and ground conductivity [5]. For this case study the technical data for double circuit transmission line between "Mahshahr S.S" and "Fajr II S.S" can be found in [4].

With reference to the PSCAD/EMTDC, Bergeron line model is selected. Transmission line model is transposed frequency dependent phase model based on travelling time and characteristic impedance of the line. The transmission line detail modeling for electromagnetic transient studies can be found in [6].

The $25 \mathrm{~km}$ double circuit transmission line is arranged according to Fig. 2. Type of the tower is T2K15 with double bundled Curlew as main conductor and Curlew core as shield conductor.

\section{B. 400/132KV Power Transformer}

Transformer models are represented with several technical data: MVA rating, wingding configuration and voltage, tap change range and normal setting, leakage reactance between windings, knee point of transformer core saturation characteristic in per unit of rate flux or voltage, and estimated saturated air core reactance [5]. The transformer detail modeling for transient studies can be found in [7] and [8].

The 315 MVA, 400/132kV, transformers are represented by saturable transformer models with two H.V. windings. The saturation characteristics of these transformers are determined. The parameters of the pre-modeled transformer block in the software are adjusted based on manufacturer's technical specification. The technical specification data can be found in [4].

\section{Infinite Bus}

Infinite bus can be described as an ideal 3 phase voltage source with a internal resistance according to network Thevenin's theorem impedance from the "Mahshahr S.S." System data can be found in [4].

\section{Circuit-Breaker}

In this study, breakers are classified as simple switch models, which change branch resistance between two given values. They are controlled through an input control signal.

The ON and OFF resistances themselves cannot be changed dynamically during the run [9]. Highly non-linear arc characteristics, which can occur in actual breakers, are not modeled in these components.

In this substation, the insulation creepage of the circuit-breaker can withstand switching over voltages up to $1050 \mathrm{kV}$ (Fig .3). Much other circuit breaker information can be found in [4].
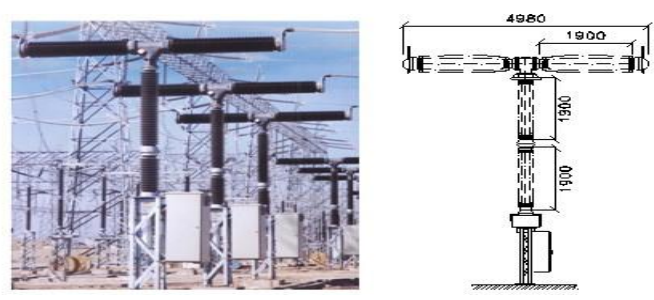

Fig. 3. 400kV Circuit-breakers installed in "FajrII S.S"

\section{RESULT AND DISCUSSION}

Actually, thirteen different switching scenarios have been 
considered and analyzed in [4]. These scenarios include different states of switching conditions like existence or absence of short-circuit, re-closing, re-opening, no load transformer and etc. In this paper only five scenarios are presented. These are the main cases and other eight conditions are split from these five.

\section{A. Theory of Switching Over-Voltages}

The main factor that causes the switching abnormal over voltage is release of trapped magnetic energy. It is supposed that at the time the current chopping occurs the instantaneous current is I0. It flows in the transformer winding and is associated with a certain amount of magnetic energy (Eq. 1) [2].

$$
\text { Energy }=\frac{1}{2} L_{m} I_{0}{ }^{2}
$$

where, $L_{m}$ is magnetizing inductance.

Because of value of $L_{m}$ is very large, the current cannot cease suddenly in such an inductive circuit [2]. The current is diverted into the capacitance of the transformer winding and capacitance of the connection between switch and transformer. The energy from the magnetic field of the transformer is transferred to the electric field of the capacitance.

The peak voltage reached across the capacitor and therefore across the winding, is given by (2).

$$
V_{p}=I_{0} \times Z_{0}
$$

where, $Z_{0}$ is the system surge impedance and can be calculated using (3), and $V_{p}$ is the over voltage peak value.

$$
Z_{0}=\sqrt{\frac{L_{m}}{C}}
$$

where, $C$ is the effective capacitance. The effective capacitance will vary depending on the type of winding and the insulation.

It can be concluded from (2) and (3) that the transient voltage is independent of the system voltage. In fact, the over-voltage value would not reach nearly as high as the value obtained from the (2). Losses are one reason causing the damping, but more important reason is that only a fraction of the energy trapped in the core at the time of chop is released [2] (Fig. 4).

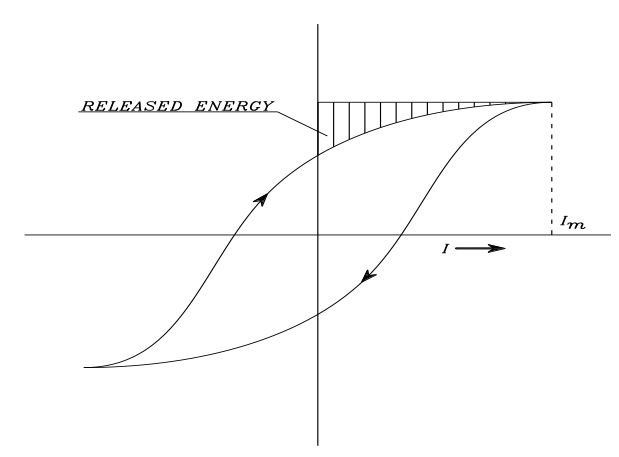

Fig. 4. Energy released by a transformer core when the magnetizing current is chopped

Practically in the worst case, chopping current at the peak, the chopping voltage will not exceed $55 \%$ of what calculated before. Based on this fact, switching voltage can be obtained from (4) [2].

$$
\begin{aligned}
v_{(s)}= & \frac{s V_{(0)}}{s^{2}+\frac{s}{R C}+\frac{1}{L_{m} C}+\frac{V_{(0)}}{R C} \frac{1}{s^{2}+\frac{s}{R C}+\frac{1}{L_{m} C}}} \\
& -\frac{I_{0}}{C \cdot\left[s^{2}+\frac{s}{R C}+\frac{1}{L_{m} C}\right]}
\end{aligned}
$$

\section{B. Simulation and Results}

In this section five scenarios that lead to switching over-voltage are presented. It should be considered that only the worst phase will be presented in each case. According to simulation the worst cases are happened for middle circuit breaker in each " $11 \frac{1}{2}$ breaker" switchgear bay.

Case.1: Simulation of Switching of C.B., During Normal Operation:

In the first scenario system is in a stable operating condition. Before starting the simulation these conditions are applied to the system: $400 \mathrm{kV}$ transmission line is connected to system. Circuit-breakers "=C01-QA1, =C02-QA1, $=\mathrm{C} 01-\mathrm{QA} 2$ and =C02-QA2" are closed and "=C01-QA3 and =C02-QA3" are opened. Tap of the transformers are regulated on $1.05 .132 \mathrm{kV}$ load outgoings are connected and Fajr power plant feeders are disconnected from the system.

In the moment of 1 second =C01-QA3 is closed and after 0.1 seconds reopened. Again after about 0.9 seconds, by closing C.B. -QA3 the system becomes stable again. According to Fig. 5, there is a little over-voltage in phase c.

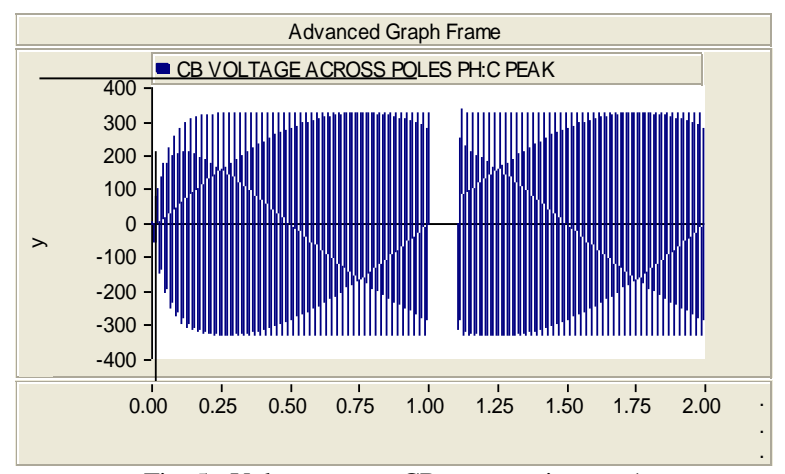

Fig. 5. Voltage across $\mathrm{CB}$ contacts in case. 1

Case.2: Simulation of switching of C.B., during short-circuit:

In the second scenario system is in a stable operating condition. Before starting the simulation these conditions are applied to the system: $400 \mathrm{kV}$ transmission line is connected to system. Circuit-breakers "=C02-QA1, =C02-QA2, $=\mathrm{C} 02-\mathrm{QA} 3$ and =C03-QA3" are closed and "=C01-QA1 and =C01-QA2" are opened. Tap of the transformers are regulated on $1.05 .132 \mathrm{kV}$ outgoing feeders are connected and "Fajr II power plant" feeders also are connected to the system.

Three phase short-circuit is occurred at the end of the Cable1. After 0.1 seconds =C01-QA3 and =E5-QA1 are tripped and opened. In the moment of 1.4 seconds fault is cleared. Again after about 0.6 seconds, the system becomes stable again. According to Fig. 6, the maximum peak over-voltage that occurs is about $370 \mathrm{kV}$ phase to earth equal 
to 1.17 times greater than normal operating phase voltage.

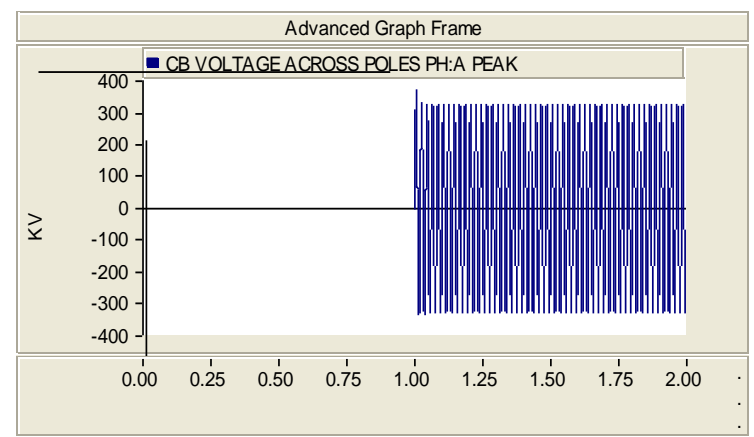

Fig. 6. Voltage across CB contacts in case.2.

Case.3: Simulation of switching and reclosing of C.B., in presence of no-load transformer:

In the third scenario system is in no load operating condition. Before starting the simulation these conditions are applied to the system: Transformers operate in no load condition and all of the $132 \mathrm{kV}$ outgoings are disconnected. Cables are disconnected from $132 \mathrm{kV}$ busbar. Circuit-breakers "=C02-QA1, =C02-QA2, =C01-QA1, =C01-QA2 and $=\mathrm{C} 01-\mathrm{QA} 3$ " are closed and "=C02-QA3" is opened. Tap of the transformers are regulated on 1.05.

In the moment of 0.999 seconds $=\mathrm{C} 01-\mathrm{QA} 3$ is opened and in the moment of 1.0653 seconds reclosed. Again in the moment of 2 seconds, the system becomes stable again. According to Fig. 7, the maximum peak over-voltage that occurs is about $428 \mathrm{kV}$ phase to earth equal to 1.86 times greater than normal operating phase voltage.

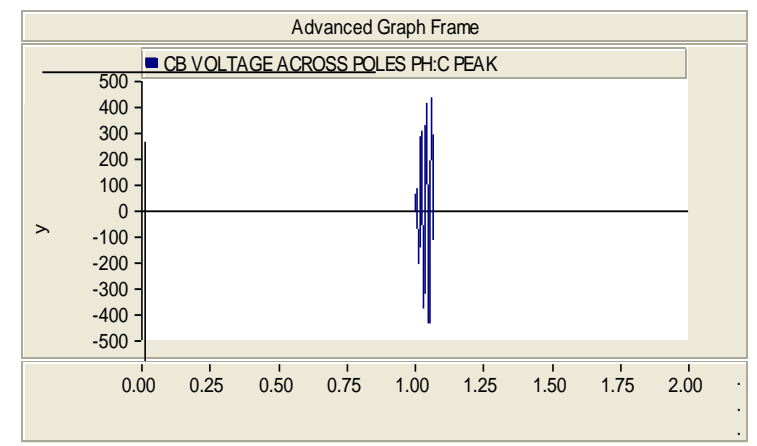

Fig. 7. Voltage across $\mathrm{CB}$ contacts in case. 3

Case.4: Simulation of switching, reclosing and reopening of C.B., in presence of no-load transformers and double circuit transmission line:

In the forth scenario system is in no load operating condition. Before starting the simulation these conditions are applied to the system: Transformers operate in no load condition and all of the $132 \mathrm{kV}$ outgoings are disconnected. Cables are disconnected from $132 \mathrm{kV}$ busbar. Circuit-breakers "=C02-QA1, =C02-QA2, =C01-QA1 and =C01-QA2" are closed and "=C02-QA3 and =C01-QA3" are opened. Tap of the transformers are regulated on 1.05.

In the moment of 0.999 seconds $=$ C01-QA 3 is closed and in the moment of 1.0653 seconds reopened. Again in the moment of 2 seconds, the system becomes stable again. According to Fig. 8, the maximum peak over-voltage that occurs is about $710 \mathrm{kV}$ phase to earth equal to 3.08 times greater than normal operating phase voltage.

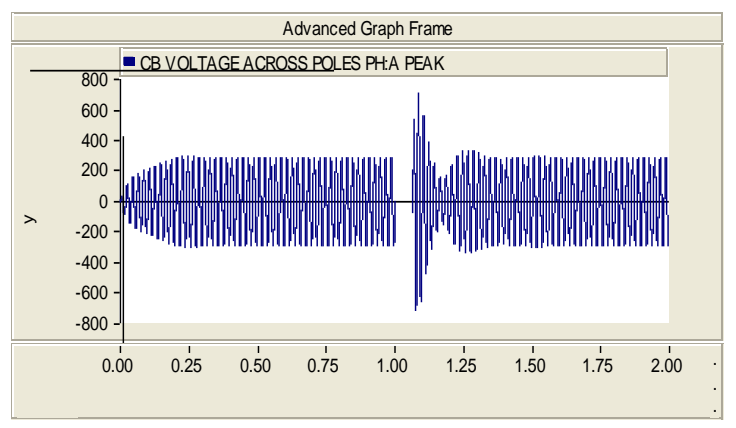

Fig. 8. Voltage across $\mathrm{CB}$ contacts in case. 4

Case.5: Simulation of switching, reclosing and reopening of C.B., in the presence of no-load transformers and single circuit transmission line:

In the last scenario system is in no load operating condition. Before starting the simulation these conditions are applied to the system: Transformers operate in no load condition and all of the $132 \mathrm{kV}$ outgoings are disconnected. Cables are disconnected from $132 \mathrm{kV}$ busbar. Circuit-breakers "=C02-QA2 and =C01-QA2" are closed and "=C02-QA1, $=\mathrm{C} 01-\mathrm{QA} 1,=\mathrm{C} 02-\mathrm{QA} 3$ and =C01-QA3" are opened. Tap of the transformers are regulated on 1.05 .

In this scenario one circuit of the overhead line is disconnected from both upstream substation and "Fajr II S.S".

In the moment of 0.999 seconds $=\mathrm{C} 01-\mathrm{QA} 3$ is closed and in the moment of 1.0653 seconds reopened. Again in the moment of 2 seconds, the system becomes stable again. According to Fig. 9, the maximum peak over-voltage that occurs is about $750 \mathrm{kV}$ phase to earth equal to 3.26 times greater than normal operating phase voltage.

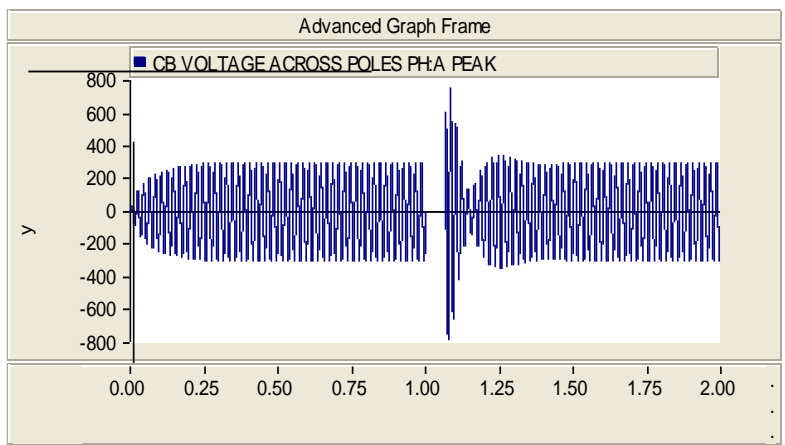

Fig. 9. Voltage across $\mathrm{CB}$ contacts in case. 5

\section{CONCLUSION}

In this study, switching over voltages for $400 \mathrm{kV}$ circuitbreakers of the "Fajr II substation" have been analyzed. System components were modeled and implemented in PSCAD/EMTDC software for further simulations. Five different case studies were defined and simulation has been done for each one. The voltage between two contacts of the middle breaker for three phases has been recorded. From above figures it can be concluded that there is some technical factors that can lower the switching over voltages. In this substation, the length of the transmission lines is the main reason. It can be observed from figures that the maximum probable switching over voltage that can occur is lower than maximum switching voltage withstood of the insulation of the 
circuit breaker. Based on this conclusion, there is no need for expensive shunt resistor or synchronizing switch for the $400 \mathrm{kV}$ circuit-breakers in the "Fajr II 400/132kV substation".

\section{ACKNOWLEDGMENT}

The first author thanks Prof. Rahimi for her valuable comments. The first author also thanks his wife, for her kindness during preparation of the paper.

\section{REFERENCES}

[1] A. F. B. Young, "Some Researches on Current Chopping in High-Voltage Circuit-Breaker," in Proc. of IEE, Part II: Power Engineering, August 1953.

[2] A. Greenwood, Electrical Transients in Power Systems, 2rd ed. John Wiley \& Sons Inc, 1991, pp.93-97.

[3] ABB Product information, 5409 722-101 en Rev.3, SWITCHSYNC F236, ABB Power Technologies AB, Dec 2005.

[4] B. Sedaghat and M. Esmi, Switching over-voltage analysis for FajrII 400/132KV GIS S.S Report, Published only for client, Fajr Petrochemical Company, October 2009.

[5] Introduction to PSCAD/EMTDC V4.1, Manitoba HVDC Research Center, Winnipeg, Canada, 2003.

[6] J. R. Marti, "Accurate Modeling of Frequency Dependent Transmission Lines in Electromagnetic Transient Simulations," IEEE Transactions on Power Apparatus and Aystems, PAS-101, Jan 1982.

[7] V. Brandwajn, H. W. Dommel, and I. I. Dommel, "Matrix Representation of Three-Phase N-Winding Transformers for Stead-State and Transient Studies," IEEE Transactions on Power Apparatus and Systems, PAS-101, June 1982.

[8] F. Leon and A. Semlyen, "Complete Transformer Model for Electromagnetic Transients," IEEE Transactions on Power Delivery, Vol.9, No.1, Jan 1994.

[9] PSCAD/EMTDC Power System Simulation Software User's Manual, Manitoba HVDC Research Center, Winnipeg, Canada, 1996.

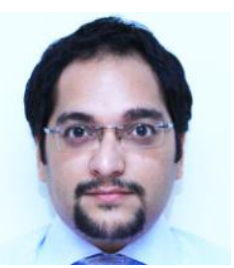

Behzad Sedaghat was born in 1982 in Tehran, Iran He received his B.Sc degree in power \& energy engineering from Tehran Polytechnic University, Tehran, Iran in 2007 and his M.Sc in renewable energy engineering from Zanjan University, Zanjan, in 2010.

He has three years experience in power \& energy systems design as an Electrical Power Substation and DG Power Plants engineer in T.P. Hermod Company, Iran. He is now with Monenco Iran consulting engineers of MAPNA Group. He has written a book entitled "Power system analysis and protection systems with PSCAD/EMTDC software" (Tehran, Tafresh University publications, 2007). His areas of research interest include: Energy \& Power System, Power System Management, Planning and Reliability, Control and Integration of Renewable Energy Plants, Application of GIS in Power System Planning, and Electric Power System Dynamics.

Mr. Sedaghat is a member of the Organization for Engineering Order of Building of Iran, Gold member of the Amirkabir University Alumni since 2007, member of the Zanjan University Superior Student Committee and member of the institute of electrical and electronics engineers (IEEE).

$\mathrm{He}$ has received the "Superior Researcher Student Honor of Zanjan University" in 2009 and the "Electrical Department MS.c Superior Student" in Zanjan University in 2010.

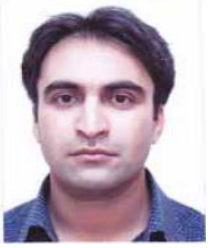

Majid Esmi was born on September 14, 1978. He received the B.Sc. degree in power engineering from Shahid Chamran University of Ahwaz, Ahwaz, Iran in 2000, and M.Sc. degree in power engineering from Sharif University of Technology , Tehran, Iran, in 2002. Currently, he is the scientific member in Azad University, Saveh branch, Saveh,Iran. 